\title{
Beijing Salt Company: The Way to Deal with the Salt Reform Program
}

\author{
Yongsheng Liu, Tong Han, Xuan Wei \\ Beijing Wuzi University, Beijing, China \\ Email: 110156392@qq.com
}

How to cite this paper: Liu, Y.S., Han, T. and Wei, X. (2016) Beijing Salt Company: The Way to Deal with the Salt Reform Program. American Journal of Industrial and Business Management, 6, 1185-1193.

http://dx.doi.org/10.4236/ajibm.2016.612109

Received: December 6, 2016

Accepted: December 25, 2016

Published: December 28, 2016

Copyright $\odot 2016$ by authors and Scientific Research Publishing Inc. This work is licensed under the Creative Commons Attribution International License (CC BY 4.0).

http://creativecommons.org/licenses/by/4.0/

\begin{abstract}
After the implementation of the Salt Industry System Reform Program, other domestic salt enterprises will compete for the market share of salt in Beijing. With the method of SWOT, this paper analyzes the advantages, disadvantages, opportunities and challenges of Beijing Salt Industry Company after the implementation of the salt industry system reform, and puts forward to seize the transition period, make close cooperation with the upstream enterprises; innovate business models, improve the service level; optimize the logistics links, reduce the cost of circulation; enrich product variety, improve the precision marketing; use new packaging, and strengthen the development of counterfeit brand countermeasure.
\end{abstract}

\section{Keywords}

Salt Industry System Reform, Salt Franchise, SWOT Analysis, Development Strategies

\section{Introduction}

On May 5, 2016, the State Council issued the "salt system reform program" (hereinafter referred to as "Salt Reform Program") which proposed the salt quality and safety and supply security as the core premise, the reform of salt production and wholesale regional restrictions and reform of salt government pricing mechanism [1]. The release of the program means that the salt reform finally will settle after ten years; salt production enterprises can enter the salt market; salt prices will have the final say in the market; cancellation of regional restrictions and market price liberalization will help to release the vitality of China's salt market. At the same time, it also brings unprecedented opportunities and challenges to the salt industry enterprises.

Beijing has a population of about 22 million, and has a good consumption of salt market. Consumers pay more attention to salt quality and safety, brand, function and 
experience. Before the implementation of salt reform program, Beijing Salt Industry Company, CNSIC (hereinafter referred to as "Beijing Salt Company") is the main business unit of salt in Beijing; after the implementation of salt reform program, with the market and price liberalization, Beijing salt market will become the battleground of other salt enterprises, and market competition will intensify. How to deal with challenges and seek development strategies are important issues to the Beijing Salt Company.

Therefore this paper explores strengths, weaknesses, opportunities and challenges of Beijing Salt Company after the implementation of salt reform program based on the SWOT analysis method, and makes recommendations to development countermeasures in the future.

\section{Clear Advantages and Disadvantages}

\subsection{The Advantages of Beijing Salt Company}

After the implementation of salt reform program, the advantages of Beijing Salt Company are mainly reflected in the following areas.

\subsubsection{Advantage of Brand}

Beijing Salt Company is a wholly-owned subsidiary of CNSIC (China National Salt Industry Corporation), as the main salt operating entity in Beijing, it has been paying more attention to the establishment of salt brand. On the one hand, Beijing Salt Company safeguard the safe supply of salt in the capital, to win the reputation with quality products and services and establish a good social image, "zhongyan" brand has become the first choice for the people of the capital [2]. On the other hand, Beijing Salt Company through the Jingdong mall, Suning tesco, GOME online sets up "zhongyan" brand flagship store, "zhongyan" brand presences in more than 100 Qingfeng Baozi shop chain stores, transfers the brand concept of "eat salt, select zhongyan", well established the "zhongyan" brand. In the "2014 Beiqing Food Industry Annual Review List" activity, which was organized by the Beiqing Group, the company's quantitative low-sodium salt products won the "Outstanding Chinese Food Innovation Product Award", which further enhanced the company's product brand advantage.

\subsubsection{Advantage of Circulation Cost}

Beijing Salt Company has a number of warehouses in Tongzhou, Fengtai, Changping, Miyun, Fangshan, storage area is about 15,000 square meters. These warehouses are standard storage at room temperature with fully automatic salt iodine installed capacity, stacking robot, radio frequency identification, and other modern equipment. In addition, the company has its own distribution vehicles, using "own vehicles mainly, the association for the secondary" distribution strategy, and now has dozens of salt professional distribution vehicles. Compared to the other salt companies that enter the Beijing market, having a professional warehouses and distribution vehicles makes Beijing Salt Company have certain circulation cost advantages in cost of circulation after the implementation of salt reform program. 


\subsubsection{Advantage of Production and Quality Control System}

Beijing Salt Company passed the ISO9001 quality certification, HACCP certification. After years of development and management, the company now has designated production qualification of various salts. In addition, the company has well-equipped salt quality inspection and testing station, use the inspection and testing method of "raw material sampling-finished sampling-stacking sampling-on-vehicle sampling" to check the salt quality seriously and make the pass rate of salt up to $100 \%$ nearly three years which ensured the quality and safety of salt.

\subsubsection{Advantage of Human Resources}

Beijing Salt Company is located in the national political and cultural center, so it has a unique advantage in talent selection. The company has 1 doctoral, 24 master's degree, 66 undergraduate, 52 below the undergraduate course, bachelor degree or above, with the proportion of 1.75:1. Bachelor degree or above with professional knowledge, undergraduate talent has the following professional and technical capabilities, making the company's talent structure is relatively reasonable.

\subsubsection{Advantage of Channel Resources}

Beijing Salt Company protects the safety of salt supply for the mission and actively explores the Beijing market. Company sales network covering the city's districts and counties, six districts and Changping, Miyun, Fangshan area are supplied by the subsidiary companies, in other districts and counties established distribution network. Company established good relationship of cooperation with the city's major supermarket chains, convenience store, organizations and institutions canteen, catering enterprises and food processing enterprises. Sales channels of Beijing Salt Company are shown in Figure 1.

At the same time, Beijing Salt Company regards Beijing Shiaote International Salt Trading Company as a platform, and cooperates with foreign salt companies, introducing dozens of original imported salt products from of the United States, Italy, France, Australia, Cyprus and other countries, which enriches the market choice and satisfy the needs of the consumer.

\subsection{The Weakness of Beijing Salt Company}

Although Beijing Salt Company has advantages, such as a well-known brand, a wealth of customer resource, it has the following aspects of the disadvantages.

\subsubsection{The Degree of Integration of Production and Marketing Needs to Strengthen}

At present, although Beijing Salt Company cooperates with dozens of fixed-point salt production enterprises, cooperation is mainly business procurement relations, production and marketing integration also has a certain potential to be tapped. Before the implementation of salt reform program, protected by the franchise system, Beijing Salt Company choices suppliers in accordance with the "the same price than quality, the same quality than price", combines production with marketing; after the implementation of salt reform 


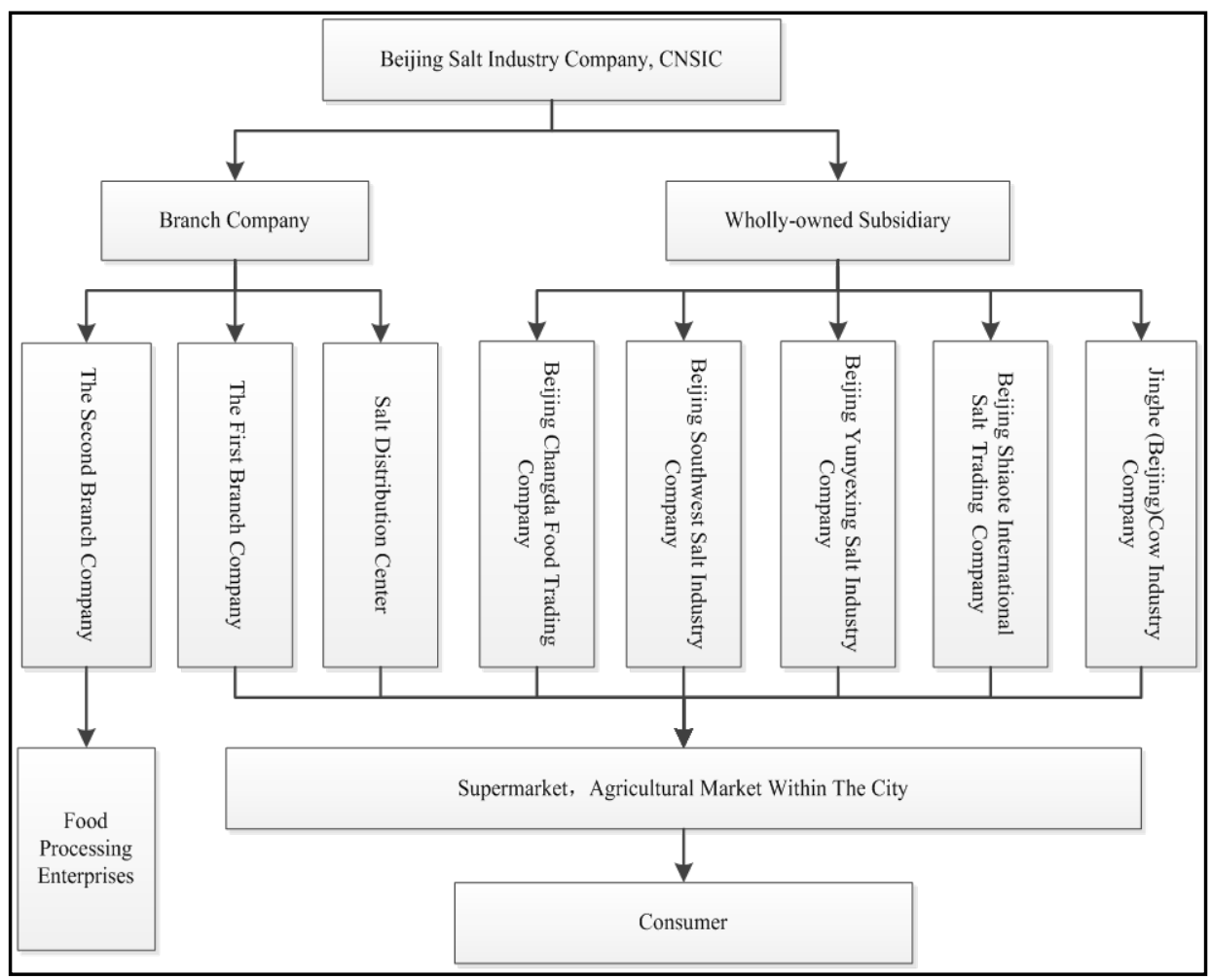

Figure 1. Sales Channels of Beijing Salt Company.

program, salt production enterprises can directly enter the salt market, then the supply and demand relations of salt production enterprises and salt sale enterprises will be a significant changes and influences production and marketing integration if has no direct assets or equity partnerships.

\subsubsection{Market Operation Ability Needs to Be Improved}

In 1978, the new historical conditions, our country's Reform and Opening-up, market economy system takes root in our country. As time goes on, almost all categories of goods have achieved market reforms, except for salt and tobacco is still under the planned economy of the national franchise and monopoly. Therefore, by the long-term impact of the salt franchise system, as with most salt companies, Beijing Salt Company compared with mature fast-moving consumer goods (FMCG) certain disparity exists yet in market business philosophy, market means and mode, market competition consciousness, crisis consciousness, innovation consciousness should further adapt to market changes.

\subsubsection{Supply Chain Integration Efficiency Needs to Be Improved}

Under the salt franchise system, although Beijing Salt Company in the salt procurement management, production operations, warehousing and distribution, marketing management, accumulated much experience and foundation, with the deepening of the market vertical integration, the constant change of consumer demand, the trend of production and marketing integration more urgent and the rapid development of "In- 
ternet+" new technologies, Beijing Salt Company in the salt supply chain model of innovation, supply chain integration is not optimized, efficiency is not high enough.

\section{Seize the Opportunity and Respond to the Challenge}

\subsection{The Opportunities of Beijing Salt Company}

After the implementation of salt reform program, the national salt market supply and demand pattern will change, at the same time it brings development opportunities for Beijing Salt Company.

\subsubsection{Opportunities in Transitional Period}

Drawing lessons from the experience of Japan and the United States, The Chinese government divided salt industry system reform into two stages, the first stage: transition period, which is from the date of publication of Salt industry system reform program to December 31, 2016. The second stage: from January 1, 2017, the market-oriented operation will be fully implemented. The first stage is a strategy ensure the security of China's salt supply and keep the marketization of salt steady, Beijing Salt Company can seize the time and take measures in the company's organizational structure, the focus of the work, mode of operation, reduce the impact of other salt companies.

\subsubsection{Policy Support}

Salt reform program pointed out that the number of fixed-point salt production enterprises and wholesale enterprises can only reduce without increase, and other types of circulation enterprises shall not engage in salt wholesale, which reduces the competitive pressure of Beijing Salt Company to a certain degree; changing the historical issues of state-owned salt enterprises into the state-owned capital category provides a good financial policy support for the transformation of Beijing Salt Company.

In addition, the salt reform program also pointed out that the every region should establish government salt reserves according to the realities of salt supply and demand. Relying on the inventory capacity of existing salt wholesale enterprise, local budget funds should be arranged for the salt reserve loan interest, management fees and other expenses support, Beijing Salt Company to assume 7700 tons of government salt reserves in Beijing, which provide a solid support for Beijing Salt Company to fulfill the political tasks as the central enterprises do.

\subsection{The Challenges of Beijing Salt Company}

The so-called opportunities always go with challenges, after the implementation of salt reform program, Beijing Salt Company should also meet the following challenges actively.

\subsubsection{Challenges of Human Resources}

Before the implementation of salt reform program, as a subcompany of the central enterprise, compared with other enterprises, Beijing Salt Company has a certain attraction on the salary system, the promotion of jobs, benefits and other aspects. However, after 
the implementation of salt reform program, the introduction of the market competition system may decrease the market share and efficiency of Beijing Salt Company, which may lead the job-hopping of employees and so on. In addition, in order to enter the Beijing salt market, other salt enterprises bound to increase the contention in the professional field, which also challenges the human resources of Beijing Salt Company.

\subsubsection{Challenges of the Market}

The market challenges faced by Beijing Salt Company include market share and market price. In terms of market share, due to the high degree of salt homogeneity, the stability of demand, before the implementation of salt reform program, salt sales enterprises occupy the market, salt manufacturers have long been coveting the share of market [3], after the implementation of salt reform program, it all depend on the ability of companies. Therefore, some salt production enterprises may choose to enter the Beijing salt market directly to seize the market share. In addition, a number of business enterprises, condiment business and business platform may also enter the market to participate in the competition by mergers and acquisitions. In terms of market price, if other salt enterprises want the share of Beijing market, low-cost sales is a major means of market development undoubtedly, especially, some salt-producing provinces or mature salt operation will use price to compete for the market. Therefore, the market price also brings great challenges to Beijing Salt Company.

\section{Take Positive Action to Deal with Reform}

\subsection{Seize the Transition Period and Deepen Cooperation with Upstream Enterprises}

Beijing Salt Company needs to seize the transition period, strengthens the combination of production and marketing by carrying out the cooperation with the salt production enterprises actively, during which makes full use of the existing marketing network and warehousing advantages to attract and promote salt production enterprise collaborative development, form the unity of production and marketing operation model by taking advantages of the reorganization of assets and mutual holding business model, jointing salt resources.

In order to maximize the benefits of the whole salt supply chain, Beijing Salt Company can also carries out strategic cooperation with the salt production enterprises, creates a Beijing Salt Company-centered salt supply chain alliance, including salt production, transportation, sales. At the same time, realizing the win-win of salt supply chain alliance enterprises by establishing a long-term effective profit distribution mechanism between upstream and downstream enterprises, enhancing the share of information and mutual trust between enterprises.

\subsection{Innovate Business Model and Improve Service Level}

First of all, Jiangsu, Guangdong, Shanghai and other provinces' salt companies, explore the chain business model actively with innovation and practice to reform the traditional salt business model in recent years. Jiangsu Salt Industry took advantages of the su salt 
chain channels, developed the electronic business platform "Su Salt Life Home". Guangdong Salt Industry used the internet as a medium, created "large kitchen of guang salt" project to purchase and sale international high-quality food [4]. Beijing Salt Company should learn from these salt companies actively in the new way of thinking, complies with changes of market, innovates business model with the guidance of demand, enhances user experience. Through the introduction of internet technology and innovative thinking, Beijing Salt Company should use the Internet Cloud Computing, Big Data and other new technologies, integration of salt business difficulties and pain points, improve the network, intelligent, information ecological system of the "Internet + salt" new business.

Secondly, as an old saying goes that firewood, rice, oil, salt, soy, vinegar and tea begins a day since Song Dynasty, Beijing Salt Company needs to cooperate with enterprises like: Haday, Totole, Jinlongyu, Beidahuang and so on, obtains the dealership of these brands in Beijing to enriches the products of "zhongyan Kitchen", furthermore promotes the viscosity of consumption .

\subsection{Optimize the Logistics Link and Reduce the Cost of Circulation}

Beijing Salt Company uses "own vehicles mainly, the association for the secondary" distribution strategy, the independent ownership of distribution vehicles has certain advantages, but different consumer channels require different distribution methods, resulting the vehicle can't be loaded at full capacity, vehicle purchase costs, maintenance cost, employee salary also increase the cost of salt circulation. In order to reduce unnecessary expenses, Beijing Salt Company should cooperate with other food companies to carries out common distribution, improves vehicle transport efficiency and reduces the cost of circulation.

\subsection{Enrich Product Variety and Improve Precision Marketing}

With the continuous improvement of domestic living standards, especially in Beijing, the proportion of high-income people is growing, the difference of consumer demand is further widening, the consumer market is further broken down. Beijing Salt Company has to provide different consumers with the products they need. Developed countries in the high-end salt market share of about $8 \%-10 \%$, and now China is the world's largest salt products consumer market, salt market consumption of about ten million tons, accounting for about $25 \%$ of global consumption [5], but the proportion of highend salt market is still very low, the future growth space is enormous.

GF Securities report pointed out that affected by the salt system reform, the high-end salt brand will be developed rapidly, and the profit will be re allocated [6]. Therefore, Beijing Salt Company has to seize the high-end salt market, introduce foreign high-end salt actively, and make a reasonable product structure with low-end salt composition researched independently. High-end boutique, mid-range diversification, and the lower end of the economic application make people have more choices [7].

Although the salt is a homogeneous product, consumer demand is relatively fixed, 
but as the main business of salt, Beijing Salt Company has to abandon the concept of "price is the sole standard for consumers of salt," and analyses of the market and the real motivation of consumers to buy carefully. With the internet of things large data to implement precise marketing strategy, Beijing Salt Company can seize the consumer "lack of what, make up what" psychology, launch marketable salt production, lead consumers to improve health with salt, enhance the consumer's sense of access, and then get the trust of consumers, to win long-term competitive advantage. As long as the precise marketing well, a drop of water can be different from other water, the salt can also be different from other salt.

\subsection{Use New Packaging to Enhance Brand Security}

More than $90 \%$ of the salt in the market of our country is plastic package, however, paper, glass containers and other packaging material are more rare. While more than 50 kinds of salt packaging in the USA, only to find a composite plastic bag, the rest are all bottles or paper [8]. On the one hand, now the Chinese pay attention to food safety and environmental safety, it is direct influence on the production and development of the enterprises whether the packaging material is environmental and it is safe or not [9]. On the other hand, plastic bag packaging design elements are not novel, lack of innovation and breakthrough, can't reach the role of publicity and promotion. Therefore, Beijing Salt Company can actively introduce and develop new salt packaging materials to meet the needs of the market.

In addition, for the safety of salt and easy to trace, Beijing Salt Company should increase the investment in anti-counterfeiting, and actively introduce advanced technology, such as two-dimensional code information technology or Radio Frequency Identification technology, using the theory of food closed supply chain to strengthen the advance warning of salt products, market access, multi-level detection and retrospective system construction. Further improve the salt traceability management system to ensure the safety of salt and maintain the salt market share.

\section{Conclusion}

With the method of SWOT, this paper analyzes the advantages, disadvantages, opportunities and challenges of Beijing Salt Company after the implementation of the salt industry system reform, and main achievements of the study are summarized as following: First, the challenges of Beijing Salt Company are greater than the opportunities. Beijing salt market will become the battleground of other salt enterprises, market competition will intensify and the market share of Beijing Salt Company will decrease. Second, with the continuous advancement of salt reform program, only through seizing the transition period, making close co-operation with the upstream enterprises; innovating business models, improving the service level; optimizing the logistics links, reducing the cost of circulation; enriching product variety, improving the precision marketing; using new packaging, strengthening the development of counterfeit brand countermeasure can Beijing Salt Company translates challenges into opportunities. 


\section{Fund Project}

Beijing Social Science Fund Project (15JGB102).

\section{References}

[1] State Council of the People's Republic of China (2016) State Council on Printing and Distributing the Notice of the Reform Plan of Salt Industry System.

[2] Beijing Salt Industry Company, CNSIC. Company Profile. http://www.bjsalt.com.cn/gsgk/gsgk/

[3] He, Y.S. (2007) Study on the Reform of Monopoly System in China. Degree Thesis, Central South University, Changsha.

[4] Hu, H.J. (2016) Reform Comprehensive Started, How to Deal with the Reform of Salt Company? China Salt Industry, No. 8, 32-35.

[5] Phoenix Finance (2016) United States Morton Company and Shanghai Salt Industry Company Cooperation, Expand China's High-End Salt Market. http://finance.ifeng.com/a/20141016/13190014_0.shtml

[6] Hou, J. (2016) Salt Industry System Reform Release after More than Ten Years. China Economic Weekly, No. 19, 54-56.

[7] Wu, F.J. (2016) Discussion on the Countermeasures of Salt Industry System Reform. China Salt Industry, No. 1, 37-40.

[8] China Salt Industry Association (2016) Jiangsu Salt Industry Company Inspect the American and Canada Salt Company. http://www.cnsalt.cn/special_d.asp?id=5609

[9] Journal Reporter (2015) Condiment Packaging Presents New Features Design and Material Creativity Leveraging the Infinite Market. Food Science, No. 9, 298.

\section{Submit or recommend next manuscript to SCIRP and we will provide best service for you:}

Accepting pre-submission inquiries through Email, Facebook, LinkedIn, Twitter, etc.

A wide selection of journals (inclusive of 9 subjects, more than 200 journals)

Providing 24-hour high-quality service

User-friendly online submission system

Fair and swift peer-review system

Efficient typesetting and proofreading procedure

Display of the result of downloads and visits, as well as the number of cited articles

Maximum dissemination of your research work

Submit your manuscript at: http://papersubmission.scirp.org/

Or contact ajibm@scirp.org 